\title{
Promoting Multilingual Education in Xinjiang: Challenges and Possible Solutions
}

\author{
Zhang Ping \\ Xinjiang Education Institute, Xinjiang, China; \\ Bangor University, Bangor, UK
}

\begin{abstract}
Multilingual education in Xinjiang Uyghur Autonomous Region (XUAR) has attracted attention from both the educators and scholars. The need for bilingual and multilingual education in XUAR in recent years has become even more important and urgent in order to develop regional economics and maintain stability in this very multicultural region. During the implementation of bilingual and multilingual education in XUAR, great efforts have been putting on promoting Mandarin Chinese (L2) as the language of instruction, as well as minority language (L1) and English (L3) in order to promote, strengthen, and develop it quickly. However, it is necessary to highlight the importance of maintaining the L1 and its culture, which contribute to the cultural pluralism and linguistic diversity during the promotion of bilingual and multilingual education. The possible suggestions would been made through three approaches, which are documentation, top-down revitalization, and bottom-up revitalization with reference to the XUAR situation. The model of the fourth way has been adopted to summarize the ways of maintenance and revitalization of L1 and cultures in XUAR.
\end{abstract}

Keywords: multilingual education, language, culture

\section{Introduction}

In China's Xinjiang Uyghur Autonomous Region (XUAR), the government has been making an effort to promote bilingual and multilingual education. "Bilingual education" in XUAR mostly does not refer to English and Chinese, but refers to using the Mandarin Chinese language (L2) as well as minority languages (L1) to teach school subjects. From this point, L2 and L1 should exist together during the process of bilingual education. However, in schools, most of the courses were encouraged by using the L2 as the medium of instruction by the year 2012 (Lu, 2005). That will definitely reduce the usage of L1. The less the people use this language, the more threat of death this language will face. The following figures give us a vivid picture about the languages in the world: over 6,000 languages currently exist, but half of them are in imminent danger of dying out (Kymlicka \& Patten, 2003). Almost 1,500 languages have fewer than 1,000 speakers (Kymlicka \& Patten, 2003). Crystal (2007) stated that on average at least one language must die every two weeks or so (p. 19). These figures highlight the importance of maintaining L1 during the promotion of bilingual and multilingual education. Language has a strong link with culture and having multiple languages and cultures are inherently valuable for society. Thus, during implementing the policies, it should always be considered that maintaining and inheriting the minority language and cultural diversity and letting their culture enrich this society.

Zhang Ping, ESL teacher, Xinjiang Education Institute; Doctorate Candidate, Language Education of Bangor University, UK. 


\section{Issues Related to Bilingual Education and Multilingual Education}

"Bilingual education" can be dated from Greek and Roman times and it has been accumulated into a voluminous academic literature by many researchers since the 1920's (Cummins \& Corson, 1997). The term "bilingual education" usually refers to "the use of two or more languages of instruction at some point in the student's school career" (Cummins \& Corson, 1997, p. xi). It is a model "where academic subjects are taught in both students' native language and in the dominant language of the school system" (Austin \& Sallabank, 2011, p. 296).

The aim of bilingual education can be widened into 10 examples, according to Ferguson's (1977) statements. The key words of these 10 examples are: assimilation, unification, communication, employment, identity, reconciliation, colonial existence, privileged position, status, and understanding of language and culture (Baker, 2006). Baker (2006) narrowed down these 10 aims into two according to a useful distinction: one aim is transition and the other aim is maintenance. Transitional bilingual education allows the students to use their mother tongue temporarily for better understanding of the course content, which is written in the L2, with the underlying aim of social and cultural assimilation from the minority language and culture into the L2 and culture. Maintenance bilingual education aims at fostering the students' mother tongue which are L1 and strengthening their sense of ethnic minority group identity. Furthermore, according to Baker's (2006) statement, the educational theory underlying bilingual education is that if the students start out learning educational content in their first language at the same time that they are learning the dominant language of education in their community, they will not lag behind, and will be able to transfer their learning to the dominant language when they have mastered it.

According to the different aims of bilingual education, different approaches are used to categorize the types of bilingual education. Mackey presented a highly detailed classification for 90 varieties of bilingual education (Cummins \& Corson, 1997). Baker (2006) classified bilingual education into three major forms including 10 sub-types:

1. Monolingual forms of education for bilinguals which contains mainstreaming/submersion education, mainstreaming with pull-out classes education and segregationist education. The aim of monolingual forms of bilingual education is monolingualism;

2. Weak forms of bilingual education for bilinguals that are transitional bilingual education, mainstream with foreign language teaching bilingual education and separatist bilingual education. The purpose of weak forms of bilingual education is relative monolingualism and limited monolingualism;

3. Strong forms of bilingual education for bilingualism and bi-literacy that contains immersion bilingual education, maintenance/heritage language bilingual education, two way/dual language bilingual education and mainstream bilingual. The goal of strong forms of bilingual education is bilingualism and biliteracy which tend to produce higher standards of academic performance across the curriculum and will contribute to the linguistic diversities and pluralism.

\section{The Implementation of Multilingual Education in XUAR}

In XUAR, multilingual education can be traced back to the Han period (around $200 \mathrm{AD}$ ) (Li \& Cao, 2009). Li and Huang (2004) divided development in XUAR into three stages (Feng \& Sunuodula, 2009). According to $\mathrm{Li}$ and Cao's (2009) analysis, there were four periods for promoting bilingual education: the "system 
establishment period" was from 1950 to 1965; the "stagnancy period" from 1966 to 1976, when the Cultural Revolution happened; the "recovery and development period" from 1977 to 1987; and from 1987 until present is the last period for reforming, experimenting, and accelerating the development of bilingual education. Furthermore, it has been implemented dramatically in recent five years.

In order to understand the multilingual education in XUAR, it is necessary to understand the multilingual and multicultural context in XUAR. Xinjiang Uyghur Autonomous Region has been a multilingual and multicultural region which connects Europe with Asia. It borders eight countries: Kazakhstan, Kyrghizstan, Tajikistan, Russia, the Republic of Mongolia, India, Pakistan, and Afghanistan; and three provinces or regions in China: Gansu, Qinghai, and Tibet (Tsung \& Ken, 2009). It has 13 main ethnic nationalities of 19.3 million people. According to the 2007 census, there were 12.71 million minority people that occupied $60.68 \%$ of the total population in XUAR and the number is increasing year by year. Uyghur are the largest group with 9.65 million (Liu \& Cai, 2010). There are three nationalities: Han, Hui, and Manchu who speak Mandarin Chinese; Turkic languages are spoken by the other five nationalities and these are: Uyghur, Kazak, Kirghiz, Uzbek, and Tatar; and a large amount of minority people use Russian and Tajik (Tsung \& Ken, 2009).

Thus, it can be concluded that XUAR is really a multilingual and multicultural society. With this kind of special position and combination of peoples, it is inevitable that different minority groups have to communicate and learn from each other. Different minority diversities interact and influence each other in many ways, including their language and culture. That explains why multilingual education in XUAR has a long history and has never stopped. The need for bilingual and multilingual education in XUAR in recent years has become even more important and urgent to the government. In order to maintain stability in this very multicultural region through the implementation of bilingual and multilingual education in XUAR, a series of strategies have been carried out in order to promote, strengthen, and develop it quickly in XUAR.

\section{Policy Support}

The central authorities and the regional government emphasized the particular importance of bilingual and multilingual education in XUAR. In order to adopt effective measures to speed the pace of bilingual and multilingual education in XUAR, a working forum was held in Xinjiang in 2010 by the central authorities. Giving strong support to the bilingual education in Xinjiang was treated as a national strategy.

Bilingual and multilingual education has been promoted in recent years in XUAR. Before moving further, it is necessary to define what bilingual education means and how it has been implemented. According to Baker's (2006) classification towards bilingual education as mentioned before, the bilingual education in XUAR is not only for language teaching for minority students, but also for culture mutual references and learning. This type of bilingual education in XUAR can be defined as the transitional bilingual education with the aim of shifting the use of minority language into the use of the L2 ( $\mathrm{Lu}, 2005)$. According to Baker's view towards the transitional bilingual education, the aim of this type of bilingual education is social and cultural assimilation. So, bilingual education in the XUAR context refers, in fact, to promote L2 as the medium of instruction in schools. Similarly, there is a special focus given to pre-school bilingual education with the government adopting a policy of strengthening pre-school bilingual education for minorities from 2005 (XUAR Government Document, 2005). Minority children began to study the L2 since their learning in kindergarten. The amount of the children who joined in the plan of pre-school bilingual education would increase from 93.4 thousand in 2007 to 438.2 thousand in 2012. The coverage of pre-school bilingual education for minority children will reach more than $85 \%$ (Zhang, 
2010). They are encouraged to speak L2 in order to improve their L2 proficiency. With these policies put into practice, the minority students usually speak L2 in schools, even in public, instead of their own mother tongue in order to get high marks in their HSK (hàn yŭ shǔi píng kăo shì; Test for Mandarin Chinese Proficiency) and have more opportunities in the future employment.

\section{Finance Support}

Until 2012, the government planned to spend 5,100 million RMB on the development of this unique XUAR bilingual/multilingual education including the facilities being updated and supplemented. According to the policy of further promoting economic and social development in XUAR (Central Government Document, 2007), the central government planned to invest 3.72 billion RMB to develop the pre-school bilingual education for minority children during 2008 to 2012 . There would be 2,237 new bilingual kindergartens for minority children's pre-school education built by 2012 (Zhang, 2010).

\section{The Special Plan for Training Bilingual Teachers}

There are two kinds of special plans for training bilingual teachers. One is for training the college students to supplement the bilingual teachers. The other is to train the current bilingual teachers to be more qualified.

Until the end of 2009, 13.73 million minority students had not received bilingual education. However, there were only 28 thousand bilingual teachers in XUAR. The shortage of skilled bilingual teachers is one of the biggest obstacles in the implementation of bilingual education in XUAR. Thus, one special plan is training normal students for free to supplement the bilingual teachers from 2010. According to the China Youth Daily (2011), the policy of training normal students for free in XUAR was applied in February, 2010. There would be 1,100 students coming to the designated city or town to support teaching, among 6,000 students from 2011 to 2013. It is the first region to have this kind of special treatment in China. These bilingual teachers will be the contributors to the bilingual education in XUAR.

The other special plan is for training the current bilingual teachers and making a related policy for the requirements of bilingual teachers. The minority teacher who cannot meet the requirement of HSK eight in the university will not have the chance to have higher professional ranks and titles if they have been bilingual teachers in one certain school now (XUAR Government Document, 1999; You, 2006). Meanwhile, the other special plan being implemented is training the current bilingual teachers for free with particular effort on the four districts of Nanjiang primary and secondary schools. This was put into practice from 2007. There were 500 bilingual teachers training for free from 2007 increasing to 1,100 in 2009 (China Youth Daily, 2011). Thus, the target of this training plan is only for minority teachers in schools. These plans and strategies mean to help to improve the minority students' proficiency of Mandarin Chinese, meanwhile, quicken the pace of bilingual and multilingual education in Xinjiang.

\section{The Dilemma for Minority Language Users: The Mainstream Language Versus the Minority Language During the Implementation of Multilingual Education in XUAR}

As referred to in the second part of this essay, there were 12.71 million minority people, $60.68 \%$ of the total population of 19.3 million, according to 2007 census in XUAR. It can be concluded that the "minority people" are the real majority people in XUAR context. However, with the promotion of L2 through the "multilingual/bilingual education," their language use was declining. 
Language and culture are intricately interwoven and cannot be separated without losing the significance of either language or culture (Jiang, 2000). Language is a part of culture and also culture can be performed and expressed by language. Language is an irreplaceable cultural wealth (Reyhner, 1996). Thus, in XUAR context, minority language is the root of minority cultural and spiritual heritage for all the minority people, even for all people. "Language is tied so closely to their sense of self-personality, ways of thinking, group identity, religious beliefs, and cultural rituals, formal and informal" (Crawford, 1996, p. 47).

However, on the one hand, the minority people feel threatened in the promotion of bilingual and multilingual education. They fear that this would result in the loss of their cultural identity. They realize that some of the minority people cannot speak and write their own minority language. They said they need to maintain and develop their minority language and culture. They want to retain their cultural strengths. On the other hand, the mainstream language is the L2 which was adopted by more and more minority people. They learn the L2 for gaining more chances to communicate and obtaining more information. Some choose the dominant language- - Han language to communicate even within the group. They learn the mainstream language which is L2 and culture in order to have more opportunities in their future careers. L2 is treated as a symbol of upper class, social elite, well-educated and is an effective way for wider communication for minority people in XUAR. They want their children to learn the L2 fully, too. With the economic and technological development, learning and mastering the L2 which is the mainstream language and culture in XUAR can be treated as a way or a tool to enter into the modern elite group. Learning Mandarin is a necessity for them and it enhances the need for learning and using L2.

The dilemma between learning mainstream language versus learning minority language is facing the minority students during the implementation of bilingual and multilingual education in XUAR. They have a deep attachment towards their own minority language and culture, meanwhile, they have the desire to learn mainstream language and culture in order to live and develop better. As Fase, Jaspaert, and Kroon (1992) presented they considered changes in language use as language shift and changes in language proficiency as language loss. It quickened the pace of declining use of the minority language. As Kymlicka and Patten (2003) presented "linguistics is vulnerable" (p. 212). With the promotion of bilingual and multilingual education in XUAR, the preservation and avoiding the death of L1 need to be paid much more attention to maintain the L1 and culture which contribute to the cultural pluralism and linguistic diversity, this then becomes the essential issue to consider.

\section{How to Promote Multilingual Education as Well as Maintain the Minority Language and Culture in XUAR}

The minority language and cultural diversity should be respected during the promotion of multilingual education in XUAR. Fishman (1991, p. 82) highlighted that "efforts to restore L1 should be voluntary and 'facilitating and enabling' rather than 'compulsory and punitive' and that bilingualism should be viewed as life enriching and a bridge to other cultures" (as cited in Reyhner, 1999, p. 1). Crystal (2011) suggested that maintaining the L1 and minority culture can be approached in three parts: documentation, top-down revitalization, and bottom-up revitalization (see Figure 1). These will be discussed with reference to the XUAR situation.

\section{Documentation}

Crystal (2005) insisted that "small languages need every ounce of linguistic energy they can get" (p. 8) and "we should let the words out" (Crystal, 2011). As for L1 in XUAR, they need good publicity and to be maintained in a positive public presence. L1 can be written in various ways to get the words out and to show 
their culture to all the people. Using L1 in writing dictionaries, legends, songs, dances, and dramas can be regarded as good ways to maintain minority language and culture. Making use of the internet as a truly public statement to maintain minority language diversity is another strong and economical way. Meanwhile, the mass media, for instance, using newspapers, movies, radio programs, and TV programs can also be used as a tool to promote consciousness of maintaining L1 and cultures. All kinds of possible means can be done to foster community-based approaches to stimulate consciousness of maintaining L1 and cultures both among minority language speakers and among the L2 speakers.

\section{Top-Down Revitalization}

Bilingual and multilingual education in XUAR is treated as one of the strategies for the unity and security of Xinjiang for the government. However, a thorough account should be given on what the promotion of bilingual and multilingual education would imply for minority language in XUAR. It can rarely appear to be more secure to establish a single dominant language in the whole country (Kymlicka \& Patten, 2003). Consciously having a long-term role in making efforts to preserve the minority language and culture is essential in XUAR nowadays. Some considerable way should be found to support for fulfilling the status of minority language warranted in order to maintain the L1 and cultures. Much financial support and devoting more research efforts toward investigating a community-based approach will also be effective ways for maintaining L1 and cultures in XUAR. Much can be learned from the case studies of India (Bhatia \& Ritchie, 2006). Multilingualism and multiple language identities in India did not lead India to linguistic and national disintegration but "provide an impetus to the forces of national development and anti-discrimination" (Bhatia \& Ritchie, 2006, p. 804). Even the stable bilingualism and multiple language identities are regarded as one of its salient features of Indian bilingualism and multilingualism.

\section{Bottom-Up Revitalization}

Crystal (2011) presented in his public lecture that the most essential thing in revitalizing the minority language is that people themselves want to keep them alive. The minority people in XUAR themselves really want to keep their language and culture alive with the government support. Maintaining the L1 and culture require sustained community-based awareness-raising and voluntary organizations. From this point, we can learn from Welsh speakers. They really do much for preserving the welsh language. Such as all the notices are written in Welsh simultaneously with an English version, holding public lectures in Welsh, hosting a week of events to celebrate St David's Day-Welsh Week. As Sharyn Williams, Vice-President Welsh Affairs and Community of Bangor Students' Union said, "This is an opportunity for Welsh people to celebrate our language and our heritage" (Bangor Students Celebrate St David's Day, 2011). We can see that the people in Welsh undoubtedly provided a fantastic opportunity to show and promote Welsh language and culture. It will be helpful for promoting linguistic and cultural diversity and multilingualism. Furthermore, providing the minority language course and training, promoting the connections between minority language, communities, and organizations can be another useful ways to maintain L1 and cultures.

The model of the fourth way (Hargreaves \& Shirley, 2009) can also be adopted to summarize the ways of maintenance and revitalization of $\mathrm{L} 1$ and cultures in XUAR as the following graph shows:

Crystal (2011), however, looked at the situation on how to maintain and revitalize the L1 in general. There is another issue that can be considered. This is looking at how L1 can be maintained and promoted in schools in the promotion of multilingual education in XUAR. 


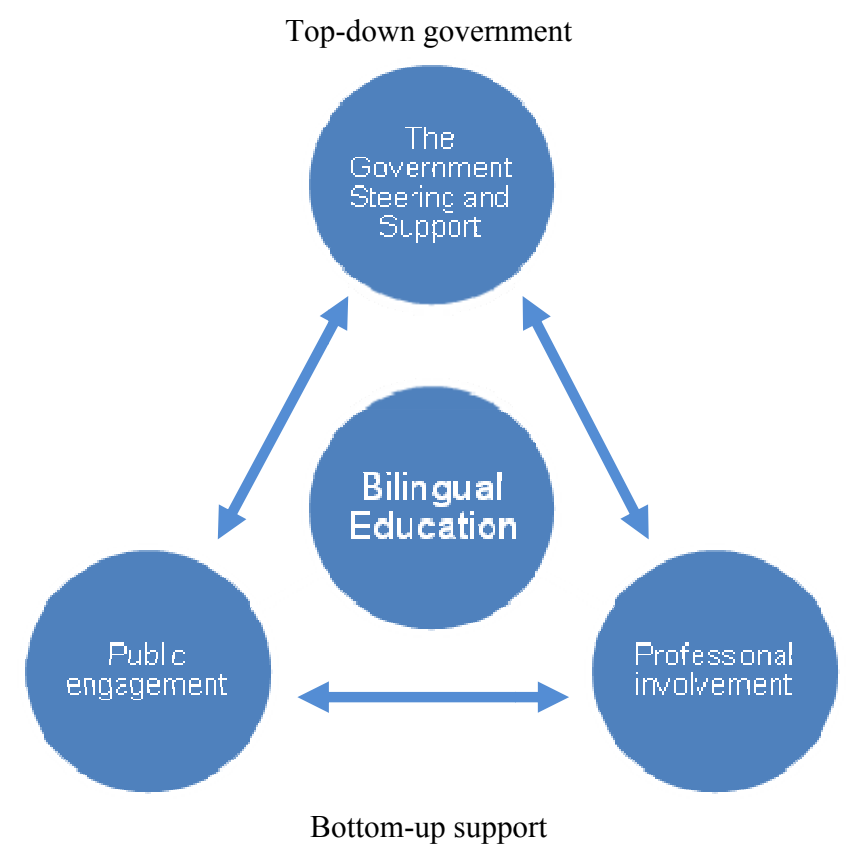

Figure 1. Approach of maintenance and revitalization of L1 and cultures in XUAR.

\section{Multilingual Education}

Achieving in the basic academic skills and skills required by modern technology in their own languages, L2 and English can be regarded as balanced multilingual education. As Baker (2006) stated that "effective bilingual/multilingual education is not a simple or automatic consequence of using a child's home language in school or a second language. Various home and parental, community, teacher, school, and society effects may act and interact to make bilingual/multilingual education more or less effective" (p. 262).

\section{The Attitude}

Having a positive attitude towards minority language and culture is very important during promotion of multilingual education in XUAR. As Reyhner (1996) stated "schools that respect and support a student's language and culture are significantly more successful in educating those students" (p. 10). Constructing a theoretical base, choosing the proper teaching medium, and methods in the classroom and follow-up to training are also good ways to implement multilingual education without doing harm for maintaining L1.

\section{Parental Involvement and Family Values}

The key to maintain minority language and culture in the transmission of the language is using the L1 at homes between family members or at community social occasions (Reyhner,1999; Crystal, 2005). The parents need to consciously use the L1 within and out of home in order to keep speaking until their children can pass it on to the next generation of children. It will be helpful for ensuring the language progresses from one generation to the next. Meanwhile, parents should be positive towards another language which does not coincide with their L1.

\section{The Call for Teaching Method and Curriculum Culture Changes}

Bilingual/multilingual education schools should be teaching and learning by the medium of two or more languages and it cannot be just the use of only one language and to be recognized as bilingual/multilingual 
schools just for official. The multilingual teacher could use minority language as a medium to explain some difficult points in order to make the students understand better in their own. One of the Ramirez's (1992) bilingual/multilingual education programs' results in the United State (US) indicated that mother tongue language use in class, even in school, will not hold children back (as cited in Reyhner, 1996). It is also the time for calling curriculum culture changes to maintain minority language and culture.

\section{Qualified Bilingual Teacher Training}

Many researchers in XUAR pointed out that some of the multilingual teachers actually completely use one language to teach all the courses, because they lack of other languages' proficiency. Providing the appropriate pre-service and in service teachers' training with various forms becomes another way to preserve the L1. With qualified multilingual teachers, that will promote the multilingual education to develop in the right amount and benefit the maintenance of minority language and culture.

\section{Stimulate Voluntary Programs}

Making a friendlier environment for L1 can be treated as a way of maintaining minority language. For instance, making an effort to develop the effective multilingual programs to stimulate minority students even majority students to learn and speak the L1; promoting the use of the L1 environment, such as building some clubs, interest groups for learning, and appreciate minority language and culture; encouraging to hold some lectures in minority language; literacy can also expand the environments for minority language use beyond schools to letters, e-mail, signs, school newspapers, magazines. Those efforts will also be helpful in maintaining the minority language and culture, so as to contribute for bilingual and multilingual education in XUAR.

\section{Conclusion}

The world is driven and shaped. We should realize that, "A small language should be treated as a friend just like a small language needs every friend it can get and a small language should be welcomed and included within the community, even if their levels are $1 \%$ all over, as it were. All the population need to be involved" (Crystal, 2005, p. 17). Language loss is always a slow process with no conscious. Bilingual and multilingual education in XUAR has already achieved great progress, but if it is complementing without consideration for linguistic preservation, the loss of minority language and culture will be the cost for this promotion of multilingual education. As Crystal (2010) stated that the loss of L1, if they were to continue disappearing at the current speed, would represent a great disaster and a huge loss in culture for the world as a whole. Perhaps worse than any loss we have already experienced (Kymlicka \& Patten, 2003).

Promoting multilingual education as well as maintaining of L1 and cultures will not come easily. L1 need special love, care, and protection to keep them alive. We need to engage our hearts and heads in maintaining the L1 and cultures for the world's linguistic diversities and pluralism. In this way, it will lead multilingual education in a right and prosperous direction.

\section{References}

Austin, P. K., \& Sallabank, J. (2011). The Cambridge handbook of endangered languages. Cambridge, UK: Cambridge University Press.

Baker, C. (2006). Foundations of bilingual education and bilingualism (4th ed.). UK/USA/Canada: Multilingual Matters Ltd..

Bangor Students Celebrate St David's Day. (2016). Retrieved April 25, 2016, from http://www.bangor.ac.uk/news/full.php.en? nid $=3490 \&$ tnid $=3490$ 
Bhatia, T. K., \& Ritchie, W. C. (Eds.). (2006). Bilingualism in South Asia. The handbook of bilingualism (pp. 781-807). Malden, M.A./Oxford: Blackwell Publishers.

Central Government Document. (2007). Guanyu jinyibu cujin Xinjiang jingji shehui fazhan de ruogan yijian (Opinions on further promoting economic and social development in Xinjiang) (No. 35). (in Chinese)

China Youth Daily. (2011, January 29). Xinjiang shixing defang mianfei shifansheng zhengce (Implementation of the policy of training normal students for free in XUAR) (Vol. 3). (in Chinese)

Crawford, J. (1996). Seven hypotheses on language loss causes and cures 1. In Stabilizing indigenous languages. Flagstaff, A.Z.: Northern Arizona University.

Crystal, D. (2005, June 11). Revitalizing the Celtic languages. Journal of Celtic Language Learning, 11, 5-19 (Paper in The XI Annual Conference of the North American Association for Celtic Language Teachers, University of Wales, Bangor).

Crystal, D. (2010). Language death. Cambridge, U.K.: Cambridge University Press.

Crystal, D. (2011, March 23). Language death. Powis Hall: Bangor University.

Cummins, J., \& Corson, D. (Eds.). (1997). Bilingual education. USA: Kluwer Academic Publishers.

Fase, W., Jaspaert, K., \& Kroon, S. (1992). Maintenance and loss of minority languages. In Stabilizing indigenous languages. Flagstaff, A.Z.: Northern Arizona University.

Feng, A. W., \& Sunuodula, M. (2009). Analyzing language education policy for China's minority groups in its entirety. International Journal of Bilingual Education and Bilingualism, 12(6), 685-704.

Ferguson, C. A. (1977). Baby talk as a simplified register. In C. E. Snow \& C. A. Ferguson (Eds.), Talking to children (pp. 209-235). Cambridge, UK: Cambridge University Press.

Jiang, W. Y. (2000). The relationship between culture and language. Oxford University Press Oxford Journals, 54(4), 328-334.

Hargreaves, A., \& Shirley, D. (2009). The fourth way: The inspiring future for educational change (A joint publication with the Ontario Principal's Council and the National Staff Development Council, America).

Kymlicka, W., \& Patten, A. (2003). Language rights and political theory. Oxford, N.Y.: Oxford University Press.

Li, R. Z., \& Cao, C. M. (2009). The chronicle of thousand-year events in the bilingual education of minority nationalities in Xinjiang. Urumqi: Journal of Xinjiang Education Institute, 25(3). (in Chinese)

Li, X. L., \& Huang, Q. X. (2004). Introduction and development of the Zhuang writing system. In M. Zhou (Ed.), Language policy in the People's Republic of China: Theory and practice since 1949 (pp. 239-256). Norwell, M.A.: Kluwer Academic Publishers.

Liu, J., \& Cai, W. B. (2010). An empirical analysis of the relationships between population structure and the development space of bilingual education in Xinjiang. Journal of Bingtuan Education Institute, 20(4). (in Chinese)

Lu, Q. (2005). The study on the problem and strategies during bilingual education for minority people in Xinjiang. Journal of Xinjing Normal University, 26(2). (in Chinese)

Reyhner, J. (1996). Rationale and needs for stabilizing indigenous languages 1. In Stabilizing indigenous languages. Flagstaff, A.Z.: Northern Arizona University.

Reyhner, J. (1999). Some basics of indigenous language revitalization. Flagstaff, A.Z.: Northern Arizona University.

Teresal, M. (2003). Revitalising indigenous languages in homogenising times. Comparative Education, 39(2), 147-163.

Tsung, L. T. H., \& Ken, C. (2009). Mother tongue and bilingual minority education in China. International Journal of Bilingual Education and Bilingualism, 12(5), 549-563.

XUAR Government Document. (1999, March). The views of making great efforts on continuing education and strengthening the building of the Chinese teachers in primary and secondary school in XUAR. (in Chinese)

XUAR Government Document. (2004). On strengthening the building of college teachers in XUAR/The notice of the views of strengthening the building of college teachers in XUAR (No. 146). (in Chinese)

You, J. B. (2006). A survey on bilingual teaching and bilingual training of teachers of minority ethnic groups in Xinjiang. Journal of Xinjiang Finance and Economics University, 21(1). (in Chinese)

Zhang, Y. (2010). A survey of "pre-school bilingual education" on Xinjiang ethnic minorities from 2005 to 2009. Urumqi: Journal of Xinjiang University, 38(1). (in Chinese) 